\title{
Information Avoidance in Genetic Health: Perceptions, Norms, and Preferences
}

\author{
Patrick R. Heck \\ Michelle N. Meyer \\ Geisinger Health System
}

\begin{abstract}
Author Note
We confirm that we have reported all measures, conditions, and exclusions, and that no data were analyzed before collection was complete for each study. Data, analysis scripts, preregistrations, survey exports, and supplementary materials are available from https://osf.io/nz6ud/. All experiments were determined to be exempt from review by Geisinger's IRB.
\end{abstract}

Correspondence:

Patrick R. Heck

Geisinger Autism and Developmental Medicine Institute

120 Hamm Drive, Lewisburg, PA 17837 USA

pheck1000@gmail.com

www.patrickrheck.com

This is the accepted version (before page proofing) of a Research Article to appear in the Social Cognition special issue on health. Please cite as:

Heck, P. R., \& Meyer, M. N. (2019). Information avoidance in genetic health: Perceptions, norms, and preferences. Social Cognition, 37(3), 266-293.

https://doi.org/10.1521/soco.2019.37.3.266

Keywords: Information avoidance, social perception, moral judgment, health, genetics, rationality 


\begin{abstract}
The decision to avoid or ignore potentially useful information is common and often costly in health and genetics. Little is known, however, about how people evaluate those who choose to avoid or learn health information about themselves. Across four preregistered studies, we find that lay observers view those who avoid a genetic health result as less competent and moral, with less empathy and sympathy, and as less normative than those who choose to learn this information. These negative evaluations were less severe, but still present, when the health information was described as medically nonactionable, and depended little on the true presence or absence of a harmful gene. These findings replicated for actionable genetic health results in a large sample of clinicians who interact and discuss medical tests with patients. We suggest that avoiding information about oneself may have negative consequences for social interaction, the patient-provider relationship, and health.
\end{abstract}




\section{Information Avoidance in Genetic Health: Perceptions, Norms, and Preferences}

People often decide that they would prefer not to know information about themselves. Most people, for example, report not wanting to know details about major negative life outcomes such as the date they will die (Gigerenzer \& Garcia-Retamaro, 2017) or if they will develop Alzheimer's disease (Welkenhuysen, Evers-Kiebooms, \& Van den Berghe, 1997). In the domain of health, so-called information avoidance is prevalent (Barbour, Rintamaki, Ramsey, \& Brashers, 2012; Hightow et al., 2003; Melnyk \& Shepperd, 2012) and often costly (Emanuel et al., 2015; Golman, Hagmann, \& Loewenstein, 2017; Sweeny, Melnyk, Miller, \& Shepperd, 2010). In a representative U.S. sample, $39 \%$ of individuals said they would prefer not to know their personal risk of developing cancer (Emanuel et al., 2015). Additionally, 40\% of at-risk Australian participants and their relatives declined free testing for pathogenic $B R C A 1 / 2$ genetic variants (Keogh et al., 2004).

When health information is medically actionable, avoiding that information can increase morbidity, mortality, and healthcare system costs that could have been directed to other care (CDC, 2017; Khoury, Coates, \& Evans, 2010). Conversely, genetic screening and surgical procedures can reduce morbidity and mortality in breast and ovarian cancer for those with pathogenic BRCA1/2 variants (Finch et al., 2006; Rebbeck, Kauff, \& Domchek, 2009) and in colorectal cancer incidence and mortality for those with Lynch syndrome (Jarvinen et al., 2000). But individuals can only take risk-reducing actions if they first choose to learn their at-risk genetic status. Even when health information is not medically actionable, it may still be useful to know. Learning one's own predisposition for an untreatable disease, for example, can help people make decisions about finances, family planning, and end-of-life care. A willingness to 
learn about one's own health risks is therefore critical to the success of preventative medicine and is important to other personal and social goals.

\section{(Social) Decisions to Learn or Avoid Health Information}

Although psychological science has recently started to ask what people choose to learn about themselves and what they may deliberately ignore or avoid (Gigerenzer \& GarciaRetamaro, 2017; Hertwig \& Engell, 2016), little is known about how people evaluate others who choose to avoid or learn information. This is a notable gap in the health literature because health decisions are often made socially, that is, in the presence of at least one other person (typically a healthcare provider and/or loved one). Given that social judgments can influence decisions, behavior, and the self-image (Jordan et al., 2016; McAdams, 2013; Rom \& Conway, 2018), we ask in this research how both laypersons and clinicians judge others' health information avoidance. It may be the case that observers give people who avoid information the benefit of the doubt, perhaps by recognizing their "right not to know" (Andorno, 2004; Ndinya-Achola et al., 1995; Wilson, 2005). Conversely, perhaps people believe that more information is always better, which may result in health information avoidance being perceived as an irrational decision, a norm violation, or a reflection of dubious character. Social psychological research has shown that evaluations of social decisions typically reflect social norms (Bicchieri, 2006; Cialdini, Kallgren, \& Reno, 1991; Sparkman \& Walton, 2017) and can be used to confer or remove blame and praise, public status, and reputation (Anderson, Brion, \& Moore, 2012; Hartley et al., 2016; Heck \& Krueger, 2016, 2017; Malle, Guglielmo, \& Monroe, 2014). Consequently, if health information avoidance is perceived negatively by others, then people may anticipate or experience social pressures when deciding whether to learn about their own health. And if 
healthcare professionals negatively evaluate a patient who avoids useful health information, the care this patient receives may suffer.

Research on social perceptions and judgments, and social psychology more broadly, are important yet understudied potential contributors to decision-making in health (Klein, Shepperd, Suls, Rothman, \& Croyle, 2015). Howell and Shepperd (2017), for example, demonstrated that people who were made to feel socially excluded were more likely to engage in health information avoidance. Clinicians' affect and communication depend on how they perceive their patients (Street, Gordon, \& Haidet, 2007), and perceptions of patients' competence and likeability have been shown to predict clinicians' assessment and treatment decisions (Gerbert, 1984). Highly stigmatized conditions (e.g., obesity) are perceived negatively by established physicians and medical students alike (Hebl \& Xu, 2001; Pantenburg et al., 2012). These negative perceptions are associated with a worse patient-provider relationship (Mold \& Forbes, 2011; Puhl \& Brownell, 2001), shorter contact time (Bertakis \& Azari, 2005), reduced treatment adherence, and even patient mistrust of their doctor (Phelan et al., 2015). Conversely, reducing the stigma surrounding health conditions can improve the patient-provider relationship and reduce bias in care (Kinsler et al., 2007; Shen et al., 2016). Clinicians report greater liking for patients who are satisfied with their care, and who are healthier, than for unsatisfied and unhealthy patients (Hall, Epstein, DeCiantis, \& McNeil, 1993). We therefore believe it is important to ask how clinicians perceive patients' decisions, and how these perceptions may affect relationships, treatment, and care.

\section{Social Perceptions of Decisions to Learn or Avoid Genetic Health Information}

Across four experiments we investigated how observers — including laypeople and medical professionals - evaluate people's decisions to avoid or learn genetic health information 
about themselves. Like many other health decisions, the increasingly common decision about whether or not to undergo genetic testing is frequently observed by or disclosed to close others (e.g., family members and peers) and professionals (e.g., physicians, nurses, genetic counselors, and other clinicians). Disclosures are often shared outside of healthcare, as well: Yaniv, Benador, and Sagi (2004) reported that most people were willing to report their own unfavorable genetic status to their friends (63\% of participants), parents (61\%), siblings $(75 \%)$, a steady relationship partner (92\%), and even a new partner (81\%). Increasingly, genetic health results are being broadcast to a wider audience. The Twitter hashtag \#23andMe, for example, gathers public posts expressing the utility and rationality of learning genetic health information, concerns over this rationality, the actual decision to ignore or learn genetic test results, and even the positive or negative result of a test. Why would people publicly reveal such personal and sensitive information? These disclosures may be made in an attempt to garner social support (White \& Dorman, 2001), to seek additional information about the health risk itself (Cline \& Haynes, 2001), or for impression and self-image maintenance purposes (Leary \& Kowalski, 1990). An additional possibility is that decision-makers may behave strategically in this context: if people know or predict how others will respond to their behavior (Rom \& Conway, 2018), then they may ultimately choose to disclose information in part to shape others' perceptions of and willingness to interact with them (Jordan, Hoffman, Nowak, \& Rand, 2016; Leary \& Kowalski, 1990).

When considering genetic testing, individuals already face one difficult decision (e.g., whether to learn the information or not). Anticipating the social consequences of this decision (e.g., whether others — their friends, family, or doctor — might praise or disparage it) is an important additional element to consider when studying health information avoidance. We posit 
that given the complex, uncertain, and often social nature of genetic testing results, the choice to learn or avoid genetic health information can be cast as a social decision made under uncertainty, that is, a decision with uncertain outcomes that entails inter- and intra-personal consequences (Hastie \& Dawes, 2010; Krueger \& Massey, 2009; Krueger, Massey, \& DiDonato, 2008; Loewenstein, Thompson, \& Bazerman, 1989; Van Dijk, Wilke, Wilke, \& Metman, 1999). In four studies, we ask how observers view those who choose to avoid or learn genetic health risk information about themselves in an uncertain environment.

\section{Hypotheses and Experimental Approach}

Gigerenzer and Garcia-Retamero (2017, p. 195), summarizing Stigler (1961), described economic and political theorizing about information avoidance as follows: "valid information should not be left on the table, and in much of decision theory, more information is always better, unless the cost of search exceeds its benefit." We predicted that this sentiment may also be endorsed by lay social perceivers, clinicians, or both. Study 1 therefore tested, among laypersons, the Avoidance hypothesis, which predicted that choosing to avoid genetic health information will result in less favorable social perceptions than choosing to learn it. Studies 2 and 3 considered whether social perceptions of information avoidance depend on two important pieces of context. First, we posed the Actionability hypothesis, which predicted that the extent to which observers disparage information avoidance will depend on whether or not the associated detrimental health predisposition is medically actionable (i.e., whether or not steps can be taken to prevent or reduce the risk posed by a health condition) (Howell \& Shepperd, 2012, 2013; Yaniv et al., 2004). Specifically, we predicted that avoiding actionable results would be viewed as worse than avoiding nonactionable results. Second, we predicted via the Outcome hypothesis that social judgments might also depend on the outcome of the genetic test (i.e., whether the 
harmful gene was actually present or absent). We anticipated that information avoidance might be evaluated more harshly when a target avoids learning a gene-positive result (indicating increased risk for a future health condition) than when a target avoids learning a gene-negative result (Baron \& Hershey, 1988; Nagel, 1979; Swets, Dawes \& Monahan, 2000). Finally, we tested the generalizability of our results in a sample of clinicians at a large health system where patients are currently being invited to enroll in a free genetic health screening program.

\section{Study 1}

Study 1 investigated how people evaluate a person's decision to learn or avoid genetic health information. We also asked, independent from this decision, whether the presence or absence of a harmful genetic variant influenced participants' social judgments of a target. Including this additional manipulation allows us to ask whether social perceptions relied on the target's decision, the target's true genetic status, or both.

\section{Method}

\section{Participants}

We recruited 103 participants on Amazon Mechanical Turk (MTurk) in September, 2017. Participation eligibility was restricted to those with a $90 \%$ or greater HIT approval rating and a United States residence, and participants were paid $\$ 0.75$. Sensitivity analysis revealed that this sample size would be sufficient to detect an effect as small as $d=0.37$ with $80 \%$ power, or an effect as small as $d=0.41$ with $90 \%$ power, in a repeated-measures comparison (two-tailed test; $\alpha=.005$; see results section for alpha justification) (Faul, Erdfelder, Lang, \& Buchner, 2007). ${ }^{1}$ Medium to large effects are typical in social perception research with similar designs $(d=0.4$ 0.9) (Heck \& Krueger, 2016, 2017).

\footnotetext{
${ }^{1}$ Our preregistration specified an effect size estimate of $d=0.4$ and assumed an exclusion rate of $10 \%$. Because only a single participant met the preregistered exclusion criterion of selecting the scale midpoint for all ratings, we analyze the complete dataset for each study.
} 


\section{Design and Procedure}

On the first page of a Qualtrics-hosted survey, participants were told that they would be asked to answer a series of questions and provide ratings of four unrelated adults. Participants then rated four independently manipulated target individuals presented in randomized order. Complete stimulus text is available in the online archive for this project.

Named targets ${ }^{2}$ were introduced using descriptive text that was held constant across stimuli. This descriptive text provided clarifying, realistic context underlying the target's decision, with the goal of holding constant several of the uncertain motivations and risks surrounding genetic testing (Green et al., 2013; Widdows, 2007). The target was first described as having sought genetic testing to learn more about her ancestry, both to approximate a familiar real-world situation offered by direct-to-consumer companies like 23andMe (e.g., receiving ancestry testing before being given the opportunity to view optional genetic health results) and to clarify to participants that seeking health-relevant information was not the primary purpose of the genetic test. This ensured that targets would not be evaluated negatively for choosing to avoid information they specifically sought in the first place. Then, the target was offered genetic health information that was specified to be freely available so as not to impose a material cost on learning (Caplin \& Dean, 2015). The gene in question was described as being highly predictive of "Thioamine Acetylase Deficiency," a (fictitious) life-threatening disease previously validated as an ecologically valid target disease in behavioral studies of health decision-making (Howell, Ratliff, \& Shepperd, 2016; Howell \& Shepperd, 2016).

\footnotetext{
${ }^{2}$ All targets were given female names to hold sex constant through the project. Women have been found to be more likely than men to undergo cancer genetic testing in the United States (Childers, MaggardGibbons, Macinko, \& Childers, 2018) and to report feeling a moral responsibility to communicate their genetic risks to family members (Hallowell, 1999).
} 
Following this description, participants were exposed to the experimental manipulation: whether the target chose to avoid or learn the result of this genetic test (the Avoid and Learn conditions), or, whether or not the target carried the gene (the Gene+ and Gene-conditions). Importantly, the result of the genetic test was not specified in conditions where a decision was made (Avoid; Learn), and there was no decision in conditions where the result was specified (Gene+; Gene-).

Impressions were then measured using a two-factor framework of social perception (Fiske, Cuddy, \& Glick, 2007; Goodwin, Piazza, \& Rozin, 2014; Landy, Piazza, and Goodwin, 2016; Wojciszke, 1994), which has previously been used to measure social perceptions of decision-making under uncertainty (Heck \& Krueger, 2016, 2017; Krueger, et al., 2008). Participants provided social-perceptual ratings immediately after reading about each target on four items for competence (Intelligent, Capable, Logical, and Irrational (reverse-scored)) and another four items for morality (Trustworthy, Ethical, Principled, and Irresponsible (reversescored)) (scale ranging from "not at all" to "extremely," with a midpoint of "moderately.") All eight items were presented in random order directly below the description of the target.

Next, participants answered a series of questions about each target on the same page. As a measure of participants' own stated preference for information in this scenario, participants answered the question "If you were [Target], would you choose to view this result?" on a scale ranging from 1 (Definitely not) to 4 (Definitely yes). In the Gene+ and Gene- conditions, where there was no option for the target to view the result, this question was modified to "If you were [Target], would you want to know this result?" As a measure of normative evaluation, participants were next asked "Did [Target] make the right choice?" on a similar scale (in the Gene+ and Gene- conditions, this question was changed to "Do you think [Target] should know 
this result?"). Participants were given the option to elaborate on their normative judgment in a text box. ${ }^{3}$ Participants were then given brief descriptions of empathy and sympathy and were asked to rate how much of each they felt for the target on a scale ranging from "None at all" to "A great deal" with a midpoint of "A moderate amount." These items were included on the basis of a growing demand for empathic concern (and its evaluation) in medicine and other health contexts (Nightingale, Yarnold, \& Greenberg, 1991; Spring, Cameron, McKee, \& Todd, 2018) and were measured distinctly for theoretical reasons (Escalas \& Stern, 2003; Goetz, Keltner, \& Simon-Thomas, 2010).

After rating all targets on these measures, participants answered two questions comprising the short version of a scale designed to measure individual differences in information avoidance (Howell \& Shepperd, 2016). These items were tailored to measure information avoidance in the specific context of genetic health. ${ }^{4}$ Finally, participants answered two questions about their family history and experience with genetic testing, provided demographic information about their sex, race/ethnicity, age, education, and household income, and were then given a unique code to be entered into MTurk to complete the HIT and receive compensation.

All measures are reported in the Appendix.

\section{Results}

\section{A Note on Statistical Reporting}

Analyses were conducted in $\mathrm{R}$ using the following packages: tidyverse 1.2.1, readxl 1.1.0, effsize 0.7 .1 , psy 1.1 , Rmisc 1.5 , cowplot 0.9 .2 , ez $4.4-0$, and broom 0.4 .4 , and ggstatsplot

\footnotetext{
${ }^{3}$ Although we do not report analyses of free text responses, we make all responses available in the open dataset.

${ }^{4}$ Stems to the information avoidance scale items were filled in using ecologically valid language from Geisinger Health System's MyCode Community Health Initiative consent process. This is the same language that Geisinger patients read when deciding whether or not to participate in biobank research (Carey et al., 2016).
} 
0.0.6. All $p$-values were calculated using two-tailed statistical tests. Because some of this work was exploratory, and due to the large number of statistical tests run throughout the studies, we treat results with $p<.005$ as statistically significant and results with $.005<p<.05$ as suggestive (Benjamin et al., 2017; Krueger \& Heck, 2019; Lakens et al., 2018). We report intercorrelations between all measures in the online archive for this project. Any analysis that was not preregistered is identified by the \# symbol in superscript.

\section{Social Perception}

Competence and morality ratings were computed as mean scores of the four corresponding adjectives after reverse-scoring the appropriate items. Reliability was high within each subscale of social perception (competence: $\alpha=.81$; morality: $\alpha=.77$ ), but the two were highly correlated over all conditions and observations $(r=.85)$. For this reason, we combine competence and morality into a single aggregate measure of social-perceptual positivity here $(\alpha$ $=.89$ ) and throughout this report. Although competence and morality are theoretically distinct, participants appeared to respond nearly identically to the eight items.

In support of the Avoidance hypothesis, participants rated the target who chose to avoid genetic health information substantially less positively $(M=3.00, S D=0.83)$ than the target who chose to learn this information $(M=3.95, S D=0.64), t(102)=8.78, p<.001, d=0.87,{ }^{5} 95 \% \mathrm{CI}$ $[0.74,1.16]$. No differences were observed, however, between the target who possessed the harmful gene $(M=3.598, S D=0.60)$ and the target who did not, $(M=3.601, S D=0.63), t(102)$ $=0.05, p=.97, d=0.01,95 \% \mathrm{CI}[-0.11,0.10]$. Choosing to learn genetic health information was a more socially favorable decision than deliberately avoiding it, and it was the target's choice not

\footnotetext{
${ }^{5}$ For all repeated-measures comparisons, Cohen's $d$ values are computed in $\mathrm{R}$ using the formula for correlated measures, $d=((\mathrm{M} 1-\mathrm{M} 2) / \mathrm{SD}) / \sqrt{ }(1-r))($ Cohen, 1988).
} 
to avail herself of genetic information — not her objective genetic risk or condition — that was socially disfavored.

\section{Information Avoidance Preferences and Normative Judgment}

Participants' own stated intentions to view the health result were generally high $(M=$ 3.29 out of $4, S D=0.88)$. These preferences were significantly greater in the Learn condition ( $M$ $=3.37, S D=0.80)$ than in the Avoid condition $(M=3.20, S D=0.95), t(102)=2.89, p=.005, d=$ $0.29,95 \% \mathrm{CI}[0.05,0.28] .^{\#}$ This unexpected result suggested that participants became more likely to learn an aversive genetic health result after reading about a target who chose to learn this information than after reading about a target who chose to avoid it. Participants clearly favored the decision to learn the genetic health result as the "right choice" ( $M=3.45$ out of $4, S D$ $=0.74)$ compared to the decision to avoid the result $(M=2.22, S D=1.01), t(102)=8.87, p<$ $.001, d=0.87,95 \%$ CI $[0.95,1.50]$.

\section{Empathy and Sympathy}

Over all conditions and observations, empathy and sympathy ratings were highly correlated, $r=0.79$. We therefore report these measures in aggregate and confirm that the results do not differ when empathy and sympathy are analyzed separately. Participants reported feeling greater empathy and sympathy for the target in the Learn condition $(M=3.32, S D=1.14)$ than for the target in the Avoid condition $(M=2.79, S D=1.17), t(102)=4.94, p<.001, d=0.49$, $95 \%$ CI $[0.32,0.74]$. Participants also reported feeling more empathy and sympathy for the target who carried the harmful gene $(M=3.85, S D=0.94)$ than for the target who did not $(M=2.70$, $S D=1.11), t(102)=10.35, p<.001, d=1.02,95 \% \mathrm{CI}[0.93,1.38]$. The result that participants reported greater empathy and sympathy for Gene+ targets than for Gene- targets, but did not 
discriminate between these targets' competence and morality, suggests a degree of discriminant validity in these measures.

\section{Egocentrism in Social Judgments of Information Avoidance}

Finally, we asked whether individual differences in participants' own information avoidance scale scores, collected after having rated all four targets, predicted social perceptions of the targets. Following from past research on social perceptions, we expected participants' judgments to be partially egocentric, that is, that participants who scored high on information avoidance would favor a target who chooses information avoidance (and vice versa). After aggregating the two information avoidance scale items (reverse-scoring where appropriate; $r=$ $.67)$, we correlated the resulting measure with the combined competence and morality ratings of each target separately within each condition. Indeed, social perceptions were positively associated with participants' information avoidance scale scores in the Avoid condition, $r(101)=$ $.44, p<.001$. Unsurprisingly, this relationship held in the opposite direction in the Learn condition, $r(101)=-.45, p<.001$, reflecting a degree of egocentrism in social judgments of information avoidance.

\section{Discussion}

Study 1 revealed that choosing to learn genetic health information was viewed as more competent, more moral, as the "right" choice, and with greater empathy and sympathy than choosing to avoid this information. Additionally, social perceptions of these decisions were related to participants' own information avoidance tendencies in a similar context. In two additional conditions where no decision was made, we found that individuals who possess a genetic health risk were perceived similarly to individuals who do not, though the former were viewed with greater empathy and sympathy than the latter. In Study 2, we sought to replicate the 
negative effects of information avoidance on social judgment and to extend these results by manipulating the nature of the genetic disease, namely, whether or not the associated health risk is medically actionable.

\section{Study 2}

\section{Method}

\section{Participants}

Participants $(N=101)$ were recruited on MTurk in September, 2017 with the same eligibility criteria, compensation rate, and on the basis of the same power analysis reported in Study 1. TurkGate software ensured that we did not resample participants who completed Study 1 (Goldin \& Darlow, 2013).

\section{Design and Procedure}

All instructions and measures were identical to those reported in Study 1. Unlike Study 1, however, the four targets varied along two independent dimensions: the target's decision (to avoid or learn the result) and the actionability of the genetic health result (medically actionable or nonactionable). To manipulate actionability, we retained the description of TAA Deficiency in the actionable conditions and described the associated gene as having a "known medical treatment that can prevent TAA Deficiency from developing." In the nonactionable conditions, we introduced a similar but distinct genetic disease (Thioamine Lipase (TAL) Deficiency) that was described as having no known medical treatment. Crossing these two dimensions results in a 2 (decision) $\times 2$ (actionability) repeated-measures design; each participant rated a target who chose to avoid an actionable genetic result (Avoid:Actionable), a target who chose to avoid a nonactionable result, (Avoid:Nonactionable), a target who chose to learn an actionable result 
(Learn:Actionable), and a target who chose to learn a nonactionable result

(Learn:Nonactionable).

\section{Results}

\section{Social Perception}

Positivity scores $(\alpha=.93)$ were entered into a 2 (decision: avoid or learn $) \times 2$

(actionability: actionable or nonactionable) repeated measures ANOVA. Figure 1 (top) displays positivity scores for each target. A large main effect of decision supported the Avoidance hypothesis and replicated the result of Study $1, F(1,100)=139.96, p<.001, \eta^{2}=.30, d=0.85$; targets who chose to avoid genetic health information $(M=3.00, S D=0.88)$ were perceived more negatively than targets who chose to learn this information $(M=3.90, S D=0.61)$. An unexpected main effect of actionability emerged, $F(1,100)=58.18, p<.001, \eta^{2}=.06, d=0.39$, where targets who encountered actionable genetic health risks $(M=3.28, S D=1.01)$ were perceived less favorably than similar targets facing nonactionable risks $(M=3.62, S D=0.68)$. This unexpected effect is likely driven by especially low ratings given to those in the Avoid:Actionable condition (see Figure 1, top). 

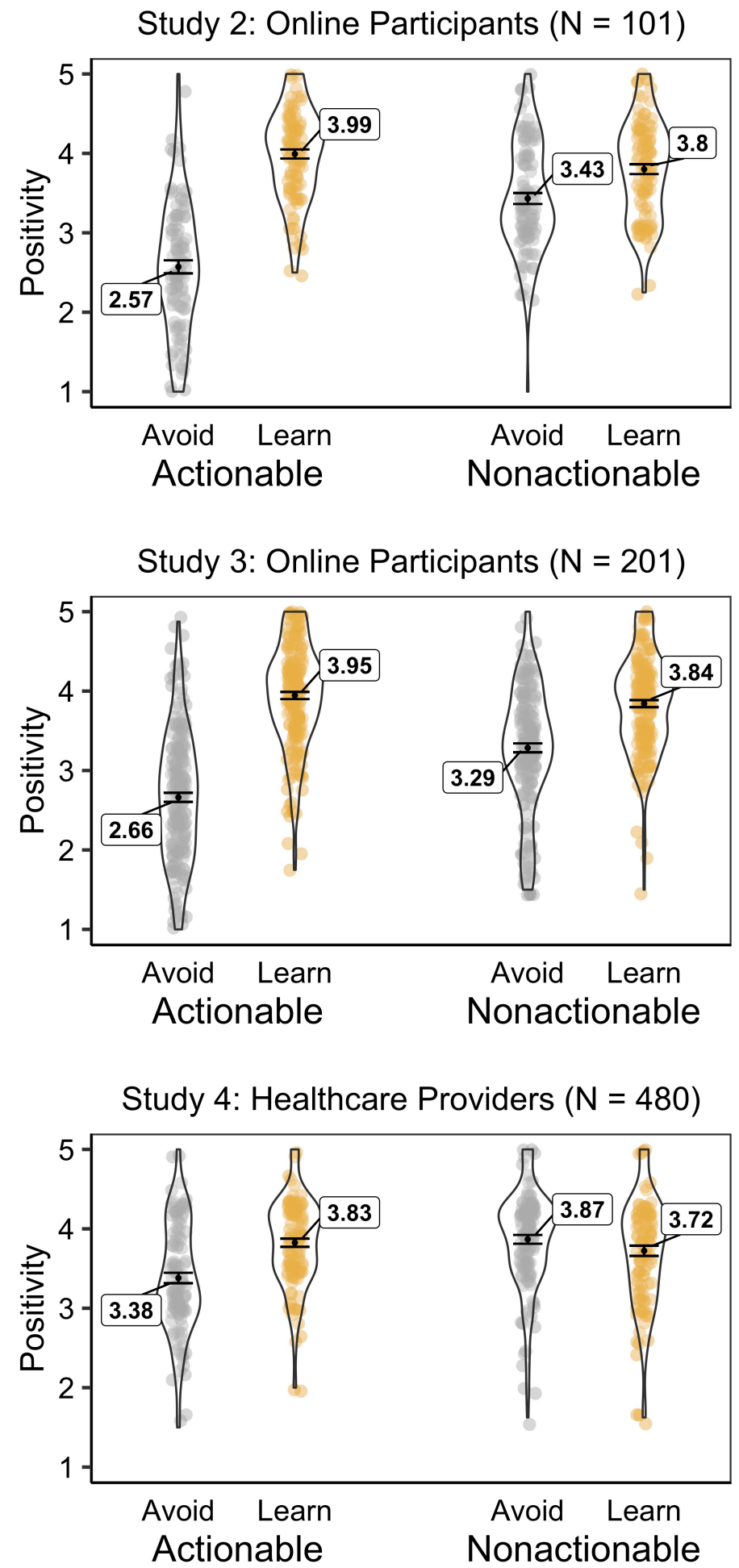

Figure 1. Social-perceptual positivity (combined competence and morality) ratings of targets who chose to learn or avoid actionable or nonactionable results in a within-subjects (Study 2, top), mixed (Study 3, middle), and fully between-subjects (Study 4, bottom) design. Black dots and error bars display the scale mean and $+/-1$ sem, respectively. 
Critically, the significant decision $\times$ actionability interaction effect supported the Actionability hypothesis, $F(1,100)=105.38, p<.001, \eta^{2}=.13$, suggesting that perceptions of information avoidance depended on the health result's actionability. Ignoring actionable information $(M=2.57, S D=0.83)$ was perceived much more negatively than ignoring nonactionable information $(M=3.43, S D=0.69), t(100)=9.87, p<.001, d=0.98,95 \% \mathrm{CI}$ $[0.69,1.03] .^{\#}$ Even when considering medically nonactionable results, however, participants favored an information-seeking target $(M=3.80, S D=0.62)$ relative to an information-avoidant one $(M=3.43, S D=0.69), t(100)=4.69, p<.001, d=0.47,95 \%$ CI $[0.21,0.53] .{ }^{\#}$ To summarize, participants favored targets who chose to learn information over those who chose to avoid it, regardless of the result's medical actionability. However, avoiding a nonactionable result was viewed more positively than avoiding an actionable one.

\section{Information Avoidance Preferences and Normative Judgment}

As in Study 1, participants' stated preferences to learn the health result were high, with the mean response falling between "probably yes" and "definitely yes" $(M=3.14, S D=0.95)$. However participants preferred learning an actionable result over a nonactionable one, $F(1,100)$ $=79.26, p<.001, \eta^{2}=.20, d=0.82$. There was no effect of the target's decision, $F(1,100)=$ $2.36, p=.13, \eta^{2}=.003, d=0.13$, and no interaction between decision and actionability, $F(1,100)$ $=2.43, p=.12, \eta^{2}=.001$. Collapsing over the decision manipulation, participants generally stated that they would learn an actionable result $(M=3.55, S D=0.72)$. Even in the two nonactionable conditions, however, average responses were closer to "probably yes" than "probably no" (Avoid:Nonactionable: $M=2.70, S D=0.99 ;$ Learn:Nonactionable: $M=2.74, S D$ $=0.95)$. 
Normative ratings of whether or not a target made "the right choice" closely tracked participants' social-perceptual ratings (Avoid:Actionable $M=1.86, S D=1.01$; Learn:Actionable $M=3.67, S D=0.55 ;$ Avoid:Nonactionable $M=2.61, S D=0.85 ;$ Learn:Nonactionable $M=$ 2.99, $S D=0.81$ ). The decision to learn a result was more normative than the decision to avoid it, $F(1,100)=94.55, p<.001, \eta^{2}=.31, d=0.71$, and this rating depended on medical actionability, $F(1,100)=85.73, p<.001, \eta^{2}=.16$. There was no main effect of actionability, $F(1,100)=0.32$, $p=.57, \eta^{2}=.001$. These results replicated the finding that information avoidance is viewed as counternormative, and corroborate the social-perceptual finding that avoiding a nonactionable result was viewed more favorably than avoiding an actionable one.

\section{Empathy and Sympathy}

We once again aggregated empathy and sympathy $(r=.77)$ into a single measure. We report descriptive statistics but forego significance testing on this measure (Gigerenzer, 2018), noting that differences between conditions are similar in pattern and magnitude to participants' social perceptual judgments. Targets who chose to avoid actionable information received substantially lower ratings $(M=2.46, S D=1.02)$ than targets who chose to avoid nonactionable information $(M=3.24, S D=1.00)$ and targets who chose to learn either result (Learn:Actionable $M=3.26, S D=1.01 ;$ Learn:Nonactionable $M=3.41, S D=0.98)$.

\section{Egocentrism in Social Judgments of Information Avoidance}

As in Study 1, a positive relationship emerged between participants' information avoidance scale score (two-item $r=.71$ ) and social perceptions of targets who chose to avoid information, $r(200)=.22, p<.003$. The corresponding negative relationship emerged when judging targets who chose to learn $(r(200)=-.24, p=.001)$. These relationships were similar within each of the four conditions ( $r$ magnitudes from .24 to .26). This analysis replicated the 
result that participants who preferred to avoid genetic health information themselves viewed information avoidant targets more positively (and vice versa).

\section{Discussion}

Study 2 replicated the result from Study 1 that avoiding a genetic health result was perceived more negatively than choosing to learn it. Additionally, we found that manipulating whether or not the genetic risk was medically actionable had consistent medium to large effects

on observers' perceptions of competence and morality, normative evaluations, and sympathy and empathy ratings. Participants' own stated preferences for information avoidance replicated the results of Yaniv et al. (2004; Study 2), who found that people reported being more likely to avoid an untreatable result than a treatable one. Interestingly, however, participants still favored learning over avoidance even when the underlying risk was explicitly described as nonactionable. In Study 3, we attempt to replicate these sizeable effects of actionability using a between-subjects design to ensure that these results cannot be explained by participants' acquiescence to task demands. Additionally, we introduce a new manipulation: whether or not the decision-making target actually carries the harmful gene.

\section{Study 3}

\section{Method}

\section{Participants}

Participants $(N=201)$ were recruited on MTurk in September, 2017 with the same eligibility criteria and compensation rate as the previous studies. The sample size was doubled in this study to account for the addition of a between-subjects manipulation. TurkGate software ensured that participants did not complete Study 1 or Study 2.

\section{Design and Procedure}


All instructions and measures were identical to those reported in Studies 1 and 2, with one exception. ${ }^{6}$ Participants were randomly assigned to rate four targets who chose to avoid or learn an actionable or nonactionable result (as in Study 2: a gene associated with TAA Deficiency or TAL Deficiency). Within each of these between-subjects conditions (Actionable ( $n$ $=103$ ) and Nonactionable $(n=98))$, the four targets varied along two independent dimensions: whether the target chose to avoid or learn the result (the target's decision) and whether the harmful gene was present or absent (the test's outcome). Crossing these two dimensions results in a 2 (actionability; between-subjects) $\times 2$ (decision; within-subjects) $\times 2$ (outcome; withinsubjects) mixed design. Thus, each participant rated targets who chose to avoid learning that the gene was present (Avoid:Present) or absent (Avoid:Absent), and targets who chose to learn that the gene was present (Learn:Present) or absent (Learn:Absent).

\section{Results}

For each group of analyses, we first report replications of support for the Avoidance and Actionability hypotheses. Then, we analyze the novel manipulation: outcome of the genetic test. In no case did we observe a significant three-way interaction between a target's decision, the gene's medical actionability, and the test's outcome. We therefore report replication analyses using 2 (decision: avoid, learn) $\times 2$ (actionability: actionable, nonactionable) mixed ANOVAs that pool data across the outcome manipulation. Because actionability was not found to interact with outcome at any level, analyses on the novel manipulation are similarly conducted using 2 (decision: avoid, learn) $\times 2$ (outcome: positive, negative) repeated-measures ANOVAs, pooling across the between-groups manipulation (actionability). To further guard against Type I errors, we refrain from decomposing the non-significant three-way interaction into separate analyses at

\footnotetext{
${ }^{6}$ All social-perception items were presented in the same order for each target, rather than being fully randomized.
} 
each level of actionability. Table 1 reports descriptive statistics for these novel analyses, and for expediency, we no longer report them in text.

Table 1. Descriptive Statistics for Decision and Outcome Manipulations (Study 3)

\section{[Insert Table 1 here]}

Note. Parentheses contain standard deviations. "Positivity" reports combined competence and morality ratings. "Egocentric Correlation" reports the correlation between participants' two-item information avoidance scale score and positivity ratings of the target. * denotes $p<.001$.

\section{Social Perception}

After combining competence and morality scores into social-perceptual positivity $(\alpha=$ .86), we found continued support for the Avoidance and Actionability hypotheses when actionability was manipulated between-subjects. Avoidant targets were judged as substantially less competent and less moral than targets who chose to learn, $F(1,199)=166.20, p<.001$, $\eta^{2}=$ $.30, d=0.84$. We once again observed a significant (but not meaningful) main effect of actionability, $F(1,199)=14.66, p<.001, \eta^{2}=.03, d=0.30$, and the critical interaction between decision and actionability, $F(1,199)=25.91, p<.001, \eta^{2}=.06$ (see Figure 1 , middle). As in Study 2, avoiding an actionable result was judged as wore than avoiding a nonactionable one, independent-groups $t(199)=5.63, p<.001, d=0.80,95 \%$ CI $[0.41,0.84]$. Even when the genetic result was nonactionable, participants continued to favor learning over avoidance, paired $t(195)=8.15, p<.001, d=0.58,95 \%$ CI $[0.42,0.69]$.

Regarding the effect of the novel manipulation on participants' social perceptions, support for the Outcome hypothesis was mixed. There was no main effect of outcome, $F(1,200)$ 
$=0.47, p=.49, \eta^{2}<.001, d=0.04$, thus replicating the finding from Study 1 that presence or absence of the pathogenic genetic variant had little bearing on observers' social judgments. We did observe a significant interaction between decision and outcome on positivity ratings, $F(1,200)=13.02, p<.001, \eta^{2}=.002$, suggesting that participants' judgments of the target's decision depended on whether the harmful gene was present or absent (see Table 1). Targets were judged more harshly if they avoided learning that the harmful gene was present than if they avoided learning that the gene was absent, $t(200)=3.11, p=.002,95 \%$ CI $[0.03,0.14]$, though this effect was small, $d=0.22$. $^{\#}$ The same pattern did not emerge in the opposite direction: targets who chose to learn the health result were perceived similarly regardless of whether the gene was present or absent, $t(200)=1.80, p=.07, d=0.13,95 \% \mathrm{CI}[-0.01,0.12] .^{\#}$

\section{Information Avoidance Preferences and Normative Judgment}

Participants' stated preferences to learn a genetic health result once again depended on medical actionability (independent from the target's decision and outcome), $F(1,199)=14.37, p$ $<.001, \eta^{2}=.06, d=0.49$, but did not depend on whether participants read about a target who carried the gene or a target who did not (independent from the target's decision and the gene's actionability), $F(1,199)=0.70, p=.40, \eta^{2}<.001, d=0.04$. Study 1 found that participants reported being more likely to choose to learn a result after reading about a target who chose to learn. Here, this effect replicated via a main effect of target's decision (independent from outcome and actionability), $F(1,199)=10.86, p=.001, \eta^{2}=.004$, with a small effect size, $d=$ 0.19 .

The results of participants' normative judgments replicated the findings from Studies 1 and 2. A large main effect of decision revealed that the decision to learn information was reliably viewed as the right choice compared to the decision to avoid it, $F(1,199)=213.38, p<.001, \eta^{2}=$ 
$.39, d=0.92$. Learning was once again viewed as more normative when the result was actionable than when it was not, $t(199)=2.94, p=.004, d=0.42,95 \%$ CI $[0.11,0.58]$.

A novel (though merely suggestive) interaction effect emerged between decision and outcome, $F(1,199)=5.30, p=.02, \eta^{2}=.002$, in which judging a target's decision as the "right choice" depended on whether the harmful gene turned out to be present or absent. As was the case for the social perception measures, information avoidance was judged as more "right" when the target avoided a negative test result than when the target avoided a positive test result, $t(200)$ $=3.70, p<.001, d=0.26,95 \%$ CI $[0.09,0.29]$. $^{\#}$ Outcome had no bearing on normative judgments of targets who chose to learn the result.

\section{Empathy and Sympathy}

The patterns of empathy and sympathy (two-item $r=.86$ ) replicated the results of Study 2 and were extended by consistent effects of the genetic test's outcome. Responses to the target's decision depended on whether the result was actionable, $F(1,199)=11.49, p<.001, \eta^{2}=.01$, with information avoidance once again receiving greater empathy and sympathy ratings when the information was nonactionable, $t(199)=3.00, p=.003, d=0.42,95 \% \mathrm{CI}[0.16,0.79] .^{\#}$

The novel manipulation produced a significant main effect of outcome, $F(1,199)=73.45$, $p<.001, \eta^{2}=.04, d=0.48$, indicating that targets carrying a harmful gene were viewed with greater empathy and sympathy than targets without the gene. We also observed a significant interaction between decision and outcome, $F(1,199)=21.97, p<.001, \eta^{2}=.01$. This interaction appeared to be driven by particularly high empathy and sympathy ratings of the target who chose to learn that she carried the harmful gene (see Table 1). This target received even higher ratings than the target who carried a harmful gene but did not learn this result, and is thus likely to unknowingly suffer from it in the future. 


\section{Egocentrism in Social Judgments of Information Avoidance}

Within and across all conditions, the familiar egocentric pattern emerged between participants' own information avoidance scale scores $(r=.68$ between the two items $)$ and combined competence and morality ratings of each target. Replicating the patterns observed in Studies 1 and 2, participants with greater information avoidance scale scores perceived avoidant targets as increasingly positive (and vice versa), ( $r$ s ranging in magnitude from .11 to .42 ).

\section{Discussion}

Study 3 replicated the negative social evaluations of a target's decision to avoid information. The moderating effect of actionability also replicated, this time in a betweensubjects design. The novel manipulation of test outcome produced small effects. Reading about the presence or absence of the harmful gene appeared not to strongly influence participants' social judgments of the targets, or participants' own stated preferences to learn this result, but it did result in greater expressed empathy and sympathy toward targets who possessed the harmful gene. Interestingly, participants appeared in part to base their social-perceptual and normative judgments of information avoidance on whether the target chose to avoid learning that a harmful gene was present or absent. Because the target could not know the result of the test before making her decision to view it, this result reflected a minor degree of outcome bias in social judgment.

In Study 4, we asked whether the heretofore large social-perceptual effects of information avoidance and medical actionability would generalize to a population of healthcare professionals who interact with patients who choose to avoid or learn genetic health results.

\section{Study 4}

We attempted to replicate the results of the previous studies in a sample of 
clinicians who have offered (or will likely soon offer) actual patients the opportunity to learn genetic health information. In 2018, Geisinger Health System announced plans to become the first health system to offer whole-exome sequencing (WES) to all patients in its primary care clinics in order to screen for actionable genetic variants that increase risk for cancers or cardiovascular disease (Andrews, 2018). This program began with a feasibility pilot in which patients in two clinics were offered the test free of co-pays or other charges. Geisinger primary care clinicians therefore are either currently asking or will soon ask patients to decide whether or not to undergo genetic health testing, and are or will be observing in real time decisions to engage in information avoidance. We reminded these clinicians of this new program and elicited their perceptions of a patient who decides to avoid or learn their genetic health risk.

\section{Method}

\section{Participants}

Participants $(N=480)$ were recruited from among 4201 clinicians at Geisinger Health System, a large, integrated health system operating in Pennsylvania and New Jersey. A recruitment email was sent to all Geisinger employees whose job title indicated that they were a physician (including medical residents), physician assistant, registered nurse, licensed practical nurse, or clinical nurse. This recruitment email briefly described Geisinger's new clinical WES program and reminded potential participants that they "are or may soon be on the front lines of offering this test," provided a link to an online survey about their "attitudes toward this new program and its participants," described the survey as fully anonymous, and offered entry into a lottery to win a $\$ 50$ Amazon gift card as an incentive for participation. We anticipated a $10 \%$ response rate, and our observed response rate (11.4\%; approximately 120 participants per condition in a fully between-subjects design) yielded $80 \%$ power to detect an effect as small as $d$ 
$=0.48$ or $90 \%$ power to detect an effect as small as $d=0.53$, in a single independent-groups comparison (two-tailed $t$-test; $\alpha=.005$ ).

\section{Design and Procedure}

Because Study 2 yielded the largest and most theoretically interesting effects, and to avoid constraining our statistical power, we dropped the outcome manipulation from Study 3. Consequently, clinicians judged a patient's decision to seek or avoid actionable or nonactionable genetic health information, replicating the design of Study 2 with some notable differences. First, because Geisinger's whole-exome sequencing (WES) program only screens for actionable genetic variants, we modified the vignettes in the actionable conditions to reflect the actual WES screening program and the vignettes in the nonactionable conditions to reflect a hypothetical scenario where someday in the future Geisinger offers to screen for nonactionable results. Second, we removed all language about ancestry testing and the fictitious disease and instead introduced the target as "a Geisinger patient" who "recently visited her doctor" and was offered "free clinical whole-exome sequencing to screen for diseases that are [not] treatable or preventable." Third, we used a fully between-subjects design to shorten the survey and remove any remaining task demands created by asking participants to rate multiple targets.

Participants completed the same dependent measures reported in the previous studies. After providing their ratings of the patient, participants completed two brief tasks for unrelated research and then answered questions about their position at Geisinger and their experience with genetics. To protect participants' potentially sensitive data, we refrained from collecting demographic data on sex, age, gender, race/ethnicity, and income to ensure that no response could be reidentified. Participants who wished to be entered into the lottery for an Amazon gift 
card were redirected to an anonymous form where their email address was collected and from which winners were randomly drawn.

\section{Results}

\section{Sample Characteristics}

Of the participants who completed the primary dependent measures $(N=480), 426$ also completed optional questions about their experience with genetics and their position at Geisinger. Nearly all participants reported that they directly interact with patients $(98.1 \%)$, and that they discuss routine tests or procedures with patients $(89.2 \%)$. Because we were interested in studying healthcare clinicians who may observe patients' decisions to get or avoid health screening, tests, and procedures, we verified that the results we report were robust to excluding participants who answered no to either of these questions." Additionally, $61.5 \%$ of the sample reported having at least some training in medical genetics, and 34.7\% reported having ordered or referred a patient for a genetic test, returned a genetic result, discussed WES screening with a patient, or ordered WES screening for a patient. Complete sample characteristics are reported in the online archive for this project.

\section{Social Perception}

Figure 1 (bottom) displays the positivity scores $(\alpha=.93)$ for each patient. A 2 (decision: avoid or learn) $\times 2$ (actionability: actionable or nonactionable) between-groups ANOVA revealed main effects in the same direction as the previous studies for the target's decision, $F(1,476)=6.36, p=.01, \eta^{2}=.01, d=0.21$, and whether or not the genetic information is actionable, $F(1,476)=10.55, p=.001, \eta^{2}=.02, d=0.29$. Critical to interpreting these main effects, however, was the decision $\times$ actionability interaction effect, $F(1,476)=24.70, \eta^{2}=.05, p$ $<.001$, which revealed a novel pattern of social perception in clinicians. Consistent with our 
previous results, the patient's decision to avoid testing for actionable results $(M=3.38, S D=$ 0.70) was perceived more negatively than her decision to get screening for these results $(M=$ $3.83, S D=0.57), t(237)=5.39, p<.001,95 \%$ CI $[0.28,0.61]$, though we note that the effect size $(d=0.70)$ was smaller than what we observed in lay observers. Clinicians, however, no longer viewed information avoidance $(M=3.87, S D=0.63)$ as less positive than learning $(M=3.72, S D$ $=0.69)$ when the target information was nonactionable, $t(239)=1.70, p=.09, d=-0.22,95 \% \mathrm{CI}$ $[-0.02,0.31] .^{7}$

\section{Information Avoidance Preferences and Normative Judgment}

Clinicians' stated preferences for learning genetic results were generally high $(M=3.00$, $S D=0.87)$ and depended only on medical actionability: participants preferred genetic health screening for actionable results $(M=3.27, S D=0.78)$ over nonactionable ones $(M=2.74, S D=$ $0.88), F(1,476)=47.81, p<.001, \eta^{2}=.09, d=0.64$. The target's decision did not influence participants' own preferences, $F(1,476)=0.80, p=.37, \eta^{2}=.001, d=0.10$, and there was no interaction effect, $F(1,476)=1.74, p=.19, \eta^{2}=.003$.

Participants' normative judgments ("Did this patient make the right choice?”) depended on the patient's decision, $F(1,476)=55.79, p<.001, \eta^{2}=.11, d=0.65$, medical actionability, $F(1,476)=4.91, p=.027, \eta^{2}=.01, d=0.18$, and critically, the interaction between them, $F(1,476)=36.98, p<.001, \eta^{2}=.07$. These ratings followed a similar pattern to the socialperceptual judgments: getting screened for actionable results $(M=3.27, S D=0.67)$ was the "right choice" to a much greater extent than avoiding these results $(M=2.35, S D=0.99), t(237)$ $=9.28, p<.001, d=1.20,95 \%$ CI $[0.73,1.12]$, but getting screened for nonactionable results $(M$

\footnotetext{
${ }^{7}$ The pattern of results was similar when restricting analyses to only those who reported working in one of the two clinics where the genetic health screening feasibility pilot is currently taking place $(n=42$ complete responses), and to only those who reported having some formal or informal training in medical genetics ( $n=262$ complete responses). ${ }^{\#}$
} 
$=3.01, S D=0.65)$ was not more normative than avoiding screening $(M=2.91, S D=0.78)$, $t(239)=1.02, p=.31, d=-0.13,95 \%$ CI $[-0.28,0.09]$.

\section{Empathy and Sympathy}

Although the pattern of combined empathy and sympathy ratings $(r=.55)$ was directionally similar to the previous studies, the reliability of these results was mixed. In our sample of clinicians, the patient who avoided testing for nonactionable results once again received greater empathy and sympathy ratings $(M=3.70, S D=0.93)$ than the patient who avoided actionable information $(M=3.26, S D=0.91), t(244)=3.68, p<.001, d=0.47,95 \% \mathrm{CI}$ $[0.20,0.66]$. However, unlike in Study 2 , these patients were not viewed with greater empathy and sympathy than the two remaining patients (Learn:Actionable $M=3.48, S D=1.08$;

Learn:Nonactionable $M=3.49, S D=0.88)$, comparison $p$ s $>.10$. These results suggest that clinicians generally expressed empathy and sympathy for any patient considering genetic health screening, though information avoidant patients received uniquely high ratings when the results were not medically actionable.

\section{Egocentrism in Social Judgments of Information Avoidance}

IA scale scores were reliable (two-item $r=.58)$, overall IA scores were low $(M=2.23$ out of $7, S D=1.90)$ and the distribution of scores was highly skewed $(84 \%$ of scores falling below the scale midpoint). Despite this distributional skew, we once again observed the predicted egocentric correlations between participants' IA scale scores and their rated positivity of the targets $(r=.29$ when rating a target who chose to avoid genetic health screening results and $r=-.30$ when rating a target who chose to get screening), and these patterns held within each condition ( $r$ magnitudes ranging from .21 to .41 ). The clinicians we studied, like the lay 
participants in our previous studies, appeared in part to evaluate others' decisions based on their own tendency to avoid genetic health information.

\section{General Discussion}

We found consistent, novel evidence that observers view health information avoidance less favorably than they view the decision to learn health information. Supporting the Avoidance hypothesis, Study 1 revealed that choosing to avoid a freely available, highly diagnostic genetic health result was viewed as less competent, less moral, and with less empathy and sympathy, than choosing to learn this result. Study 2 replicated and extended this result by showing that the strength of these social judgments depended on whether or not the health result was medically actionable. Supporting the Actionability hypothesis, online participants consistently favored targets who chose to learn information over those who chose to avoid it, but avoiding nonactionable information was less disparaged than avoiding actionable information. Study 3 replicated these results in independent samples using a between-subjects manipulation and provided mixed support for the Outcome hypothesis: the true presence or absence of a harmful gene influenced empathy and sympathy ratings, but only weakly influenced perceptions of competence and morality. Finally, Study 4 replicated these results, with one notable exception, in a sample of clinicians who regularly interact with and discuss medical tests with patients, and who will soon be routinely offering genetic health screening to patients. Although these clinicians did evaluate information avoidance more negatively than the decision to get screening for medically actionable genetic information, they appeared not to disparage information avoidance when the available information was nonactionable. These social-perceptual effects were robust to varying experimental designs and tended to be medium to large in magnitude (information avoidance social perception $d \mathrm{~s}=0.83$ (Study 1), 0.84 (Study 2), and 0.86 (Study 3) 
for lay participants; $d=0.70$ for clinicians' perceptions of avoidance compared with learning for actionable results).

Across studies, social judgments were related to lay participants' and clinicians' own stated preferences for information avoidance. Most participants — including the clinicians we studied - claimed that they would choose to learn an aversive genetic health result about themselves, even if this result was nonactionable. Despite this general preference, participants varied in an individual-difference measure of information avoidance tailored to a genetic health context. We found in all four studies that social and moral judgments of a target's behavior depended on participants' own stated tendency to avoid information: as participants' scores on the information avoidance scale increased, avoidant targets were judged as increasingly competent and moral (and vice versa). This result replicated among clinicians (who tended to

score low on the information avoidance scale). The directionality we infer from this result — that participants based their judgments of others on their own preferences - as opposed to the opposite, is an assumption made on the basis of the primacy and automaticity of social projection (Dunning \& Hayes, 1996; Krueger, 2007; Krueger \& Clement, 1994).

\section{Implications for Social Judgment}

Actionability. Following from previous conclusions about the importance of actionability (in academic research: Yaniv et al., 2004; in public policy: CDC, 2017), it is unsurprising that the strength of social judgments of information avoidance depended on the actionability of a genetic result. Extending these results, however, was the surprising and consistent finding across the first three studies that even when the health information was explicitly described as medically nonactionable, participants continued to favor learning over avoidance. This result emerged both for participants' perceptions of others and in their own 
stated preferences. One likely explanation of this result is that participants may believe medically nonactionable genomic information is useful in other, non-medical ways (e.g., planning ahead for one's financial future, partners and family, and career). Our sample of clinicians, however, challenged this conclusion: medical professionals favored learning over avoidance only when the underlying information was medically actionable. Although we do not know why this result emerged, we conjecture based on free-text responses to the patient's decision that these participants - who were recruited to the survey and invited to evaluate the patient as clinicians — saw no clear clinical benefits to learning nonactionable results, and that they believed whatever the patient chose to do was the right choice for her.

Outcome-based evaluation. We generally found limited or no support for the Outcome hypothesis. Social perceptions tended not to be influenced by whether or not the target carried harmful gene (Studies 1 and 3), and whether or not a target learned or ignored a positive result compared to a negative one (Study 3). Still, targets who carried the harmful gene received consistently greater empathy and sympathy ratings in Studies 1 and 3 (Studies 2 and 4 did not manipulate gene presence), suggesting that participants paid attention to the task and manipulations. This constellation of results raises at least one interesting and potentially useful practical strategy. Because targets with a positive genetic health result were not judged harshly simply by virtue of possessing a harmful gene and, indeed, participants reported feeling greater empathy and sympathy for them, sharing information about this result with others may be an effective method for eliciting emotional support. At least in the fictional contexts of TAA and TAL deficiency, doing so elicited feelings of empathy and sympathy from observers but had little consequence for targets' perceived rational and moral character. 
Perceptions of learning. Finally, we found that social judgments of the decision to learn a result were largely positive regardless of the experimental manipulation (see, e.g., the learn conditions in Figure 1). The decision to learn genetic information was generally perceived by laypeople and clinicians as competent and moral, as the "right" choice, and with empathy and sympathy, regardless of the nature of the result itself. Conversely, social judgments of the decision to avoid information were highly sensitive to the manipulations we studied, resulting in a novel asymmetry in social perceptions. The decision to learn appeared to largely be favored regardless of the contexts we studied here, while judgments of the decision to avoid health information relied strongly on extant or contextual factors including actionability and the perceiver's professional role. For decision-makers who are primarily concerned with others' perceptions of them, or with eliciting empathy and sympathy, these results suggest that choosing to learn health information is a safe bet, whereas choosing to ignore or avoid information may be judged more or less harshly depending on the context of the decision and the information at hand.

\section{Implications for Health and Decision-Making}

Social perceptions are necessarily implicated in the patient-provider relationship, and clinicians' perceptions of their patients can affect care and communication (Gerbert, 1984; Street et al., 2007). The presence of a stigmatized condition can degrade patients' relationship with their doctor, leading to worse health outcomes (Phelan et al., 2015; Puhl \& Brownell, 2001). If clinicians perceive information avoidance as irrational, immoral, or with less relative empathy and sympathy — as shown in Study 4 - the quality of the care they provide to those patients may suffer (Bertakis \& Azari, 2005; Rantanen et al., 2008). Study 4 provided novel evidence that medical experts, including physicians, physician assistants, nurse practitioners, and nurses, do 
socially evaluate their patients' decisions to some extent. For medically nonactionable genetic results, the clinicians we studied tended not to discern between a patient's decision to avoid or learn this information. When the results were described as medically actionable, however, clinicians consistently evaluated the target who chose to pursue information as more competent and more moral than the target who chose to avoid it. Furthermore, these judgments could be reliably predicted by participants' own information avoidance tendencies as measured by a brief scale, which may suggest that clinicians' perceptions of their patients are less neutral than many patients expect.

\section{Limitations and Constraints on Generality}

Measurement and method. In each study, we observed moderate intercorrelation between theoretically distinct measures. Although we observed discriminant validity between some of these measures, we caution against interpreting each as measuring a truly distinct construct. Within-condition and within-study intercorrelations between all measures are available as part of the online archive for this project. Additionally, it is possible that the within-subjects manipulations in Study 1-3 allowed participants to anticipate the purpose or design of the experiment. This type of design increases statistical power, but it may also exaggerate the effects if participants contrast each target with ones they had previously rated.

Generalizability. The conclusions we draw here may be limited in their generalizability for several reasons. With regard to conclusions drawn based on online participants, we note that these participants responded to fictional descriptions of target individuals in an anonymous, oneshot procedure. Although Study 4 suggests that these results generalize to a sample of medical professionals, we note that we only studied clinicians working in a single region and institution. Additionally, actual decisions to avoid genetic health results are more psychologically complex 
and more likely to occur than suggested by the hypothetical ratings we collected of willingness or intention to avoid this type of information (Howell \& Shepperd, 2016). Finally, individuals' motivations to manage interpersonal responses to their behavior may be overshadowed by other concerns, including the potential for genetic discrimination, the desire to ensure healthy offspring, or a strong anticipated negative affective response to learning aversive information.

The result that information avoidant targets received unfavorable social judgments should not be taken to mean that people have an affirmative responsibility to learn certain kinds of genetic health information, or that they should be encouraged or even forced to learn about their genes and health. We note that the social perceptions studied here are restricted to psychologists' theoretical conceptualization. We did not measure, for example, perceptions of attractiveness or desirability as a reproductive partner, which may very well differ on the basis of a genetic health result. Future research may ask how people perceive information avoidance in close others including partners and family members, and how these perceptions may affect interpersonal interactions and relationships. We further recommend that future research on social judgments of information avoidance behaviors (and these behaviors themselves) continue to study actual clinicians and healthcare providers, expand to incorporate actual patients and their decisions, and consider other health domains (i.e., outside of genetics).

\section{Conclusion}

In concluding their recent review article, Gigerenzer and Garcia-Retamaro (2017, p. 195) characterized the zeitgeist in research on information avoidance as consistent with economic and political theories of rationality: "The default is that valid information should be sought for and used. Not wanting to know, in contrast, appears counterintuitive and irrational." Our results suggest that laypeople hold this opinion for genetic health information regardless of its 
actionability, and that clinicians do so for medically actionable results. However, choosing to learn or avoid a genetic health result remains a dilemma. In the context of health, more information may not always be better (Caplin \& Dean, 2015; Hertwig \& Engell, 2016). As in any personal or social dilemma, a rational decision-maker is one who carefully weighs the available options to arrive at the best decision he or she can. It is our hope that health research will continue to consider how decision-making in health can affect a person's relationships, reputation, and care. 


\section{References}

Anderson, C., Brion, S., Moore, D. A., \& Kennedy, J. A. (2012). A status-enhancement account of overconfidence. Journal of Personality and Social Psychology, 103(4), 718-735. https://doi.org/10.1037/a0029395

Andorno, R. (2004). The right not to know: an autonomy based approach. Journal of Medical Ethics, 30(5), 435-439. https://doi.org/10.1136/jme.2002.001578

Andrews, M. (2018, May 22) Routine DNA Screening Moves Into Primary Care. Retrieved from https://www.npr.org/sections/health-shots/2018/05/22/613090774/routine-dna-screeningmoves-into-primary-care

Barbour, J. B., Rintamaki, L. S., Ramsey, J. A., \& Brashers, D. E. (2012). Avoiding health information. Journal of Health Communication, 17(2), 212-229. https://doi.org/10.1080/10810730.2011.585691

Baron, J., \& Hershey, J. C. (1988). Outcome bias in decision evaluation. Journal of Personality and Social Psychology, 54(4), 569-579. https://doi.org/10.1037/0022-3514.54.4.569

Benjamin, D. J., Berger, J. O., Johannesson, M., Nosek, B. A., Wagenmakers, E. J., Berk, R., ... \& Cesarini, D. (2018). Redefine statistical significance. Nature Human Behaviour, 2(1), 6-10. https://doi.org/10.1038/s41562-017-0189-z.

Bertakis, K. D., \& Azari, R. (2005). The impact of obesity on primary care visits. Obesity Research, 13(9), 1615-1623. https://doi.org/10.1038/oby.2005.198

Bicchieri, C. (2006). The grammar of society: the nature and dynamics of social norms. New York: Cambridge University Press. 
Caplin, A., \& Dean, M. (2015). Revealed preference, rational inattention, and costly information acquisition. American Economic Review, 105(7), 2183-2203. https://doi.org/10.1257/aer.20140117

Carey, D. J., Fetterolf, S. N., Davis, F. D., Faucett, W. A., Kirchner, H. L., Mirshahi, U., ... Ledbetter, D. H. (2016). The Geisinger MyCode community health initiative: an electronic health record-linked biobank for precision medicine research. Genetics in Medicine, 18(9), 906-913. https://doi.org/10.1038/gim.2015.187

CDC. (2017, November 21) Office of public health genomics - genomic tests and family history by levels of evidence. Retrieved from https://phgkb.cdc.gov/PHGKB/topicStartPage.action.

Childers, K. K., Maggard-Gibbons, M., Macinko, J., \& Childers, C. P. (2018). National distribution of cancer genetic testing in the united states: evidence for a gender disparity in hereditary breast and ovarian cancer. JAMA Oncology, 4(6), 876. https://doi.org/10.1001/jamaoncol.2018.0340

Cialdini, R. B., Kallgren, C. A., \& Reno, R. R. (1991). A focus theory of normative conduct: A theoretical refinement and reevaluation of the role of norms in human behavior. In Advances in Experimental Social Psychology (Vol. 24, pp. 201-234). Academic Press.

Cline, R. J. W. \& Haynes, K. M. (2001). Consumer health information seeking on the Internet: the state of the art. Health Education Research, 16(6), 671-692. https://doi.org/10.1093/her/16.6.671

Dunning, D., \& Hayes, A. F. (1996). Evidence for egocentric comparison in social judgment. Journal of Personality and Social Psychology, 71(2), 213-229. https://doi.org/10.1037/0022-3514.71.2.213 
Emanuel, A. S., Kiviniemi, M. T., Howell, J. L., Hay, J. L., Waters, E. A., Orom, H., \& Shepperd, J. A. (2015). Avoiding cancer risk information. Social Science \& Medicine, 147, 113-120. https://doi.org/10.1016/j.socscimed.2015.10.058

Escalas, J. E., \& Stern, B. B. (2003). Sympathy and empathy: emotional responses to advertising dramas. Journal of Consumer Research, 29(4), 566-578. https://doi.org/10.1086/346251

Falissard, B. (2012). psy: Various procedures used in psychometry. R package version 1.1. https://CRAN.R-project.org/package=psy

Faul, F., Erdfelder, E., Lang, A. G., \& Buchner, A. (2007). G* Power 3: A flexible statistical power analysis program for the social, behavioral, and biomedical sciences. Behavior Research Methods, 39(2), 175-191. https://doi.org/10.3758/BF03193146

Finch, A., Beiner, M., Lubinski, J., Lynch, H. T., Moller, P., Rosen, B., ... \& Kim-Sing, C. (2006). Salpingo-oophorectomy and the risk of ovarian, fallopian tube, and peritoneal cancers in women with a BRCA1 or BRCA2 Mutation. JAMA, 296(2), 185-192. doi: doi:10.1001/jama.296.2.185

Fiske, S. T., \& Cuddy, A. J. C., \& Glick, P. (2007). Universal dimensions of social cognition: Warmth and competence. Trends in Cognitive Sciences, 11, 77-83. http://dx.doi.org/10.1016/j.tics.2006.11.005

Gerbert, B. (1984). Perceived likeability and competence of simulated patients: Influence on physicians' management plans. Social Science \& Medicine, 18(12), 1053-1059. https://doi.org/10.1016/0277-9536(84)90164-3

Gigerenzer, G. (2018). Statistical rituals: the replication delusion and how we got there. Advances in Methods and Practices in Psychological Science, 1(2), 198-218. https://doi.org/10.1177/2515245918771329 
Gigerenzer, G., \& Garcia-Retamero, R. (2017). Cassandra's regret: The psychology of not wanting to know. Psychological Review, 124(2), 179-196. https://doi.org/10.1037/rev0000055

Goetz, J. L., Keltner, D., \& Simon-Thomas, E. (2010). Compassion: An evolutionary analysis and empirical review. Psychological Bulletin, 136(3), 351-374. https://doi.org/10.1037/a0018807

Goldin, G., \& Darlow, A. (2013). TurkGate (Version 0.4. 0) [Software].

Golman, R., Hagmann, D., \& Loewenstein, G. (2017). Information avoidance. Journal of Economic Literature, 55(1), 96-135.

Goodwin, G. P., Piazza, J., \& Rozin, P. (2014). Moral character predominates in person perception and evaluation. Journal of Personality and Social Psychology, 106, 148168. doi: $10.1037 / \mathrm{a} 0034726$

Green, R. C., Berg, J. S., Grody, W. W., Kalia, S. S., Korf, B. R., Martin, C. L., ... Biesecker, L. G. (2013). ACMG recommendations for reporting of incidental findings in clinical exome and genome sequencing. Genetics in Medicine, 15(7), 565-574. https://doi.org/10.1038/gim.2013.73

Hall, J. A., Epstein, A. M., DeCiantis, M. L., \& McNeil, B. J. (1993). Physicians’ liking for their patients: More evidence for the role of affect in medical care. Health Psychology, 12(2), 140-146. https://doi.org/10.1037/0278-6133.12.2.140

Hallowell, N. (1999). Doing the right thing: genetic risk and responsibility. Sociology of Health \& Illness, 21(5), 597-621. https://doi.org/10.1111/1467-9566.00175

Hartley, A. G., Furr, R. M., Helzer, E. G., Jayawickreme, E., Velasquez, K. R., \& Fleeson, W. (2016). Morality's centrality to liking, respecting, and understanding others. Social 
Psychological and Personality Science, 7(7), 648-657.

https://doi.org/10.1177/1948550616655359

Hastie, R., \& Dawes, R. M. (2001). Rational choice in an uncertain world: the psychology of judgment and decision making. Thousand Oaks, CA: Sage.

Hebl, M., \& Xu, J. (2001). Weighing the care: physicians' reactions to the size of a patient. International Journal of Obesity, 25(8), 1246-1252. https://doi.org/10.1038/sj.ijo.0801681

Heck, P. R., \& Krueger, J. I. (2016). Social perception of self-enhancement bias and error. Social Psychology, 47(6), 327-339. https://doi.org/10.1027/1864-9335/a000287

Heck, P. R., \& Krueger, J. I. (2017). Social perception in the volunteer's dilemma: role of choice, outcome, and expectation. Social Cognition, 35(5), 497-519. https://doi.org/10.1521/soco.2017.35.5.497

Hertwig, R., \& Engel, C. (2016). Homo ignorans: deliberately choosing not to know. Perspectives on Psychological Science, 11(3), 359-372. https://doi.org/10.1177/1745691616635594

Hightow, L. B., Miller, W. C., Leone, P. A., Wohl, D., Smurzynski, M., \& Kaplan, A. H. (2003). Failure to return for HIV posttest counseling in an STD clinic population. AIDS Education and Prevention, 15(3), 282-290. https://doi.org/10.1521/aeap.15.4.282.23826

Hope, R. M. (2013). Rmisc: Ryan Miscellaneous. R package version 1.5. https://CRAN.Rproject.org $/$ package $=$ Rmisc

Howell, J. L., Ratliff, K. A., \& Shepperd, J. A. (2016). Automatic attitudes and health information avoidance. Health Psychology, 35(8), 816-823. https://doi.org/10.1037/hea0000330 
Howell, J. L., \& Shepperd, J. A. (2012). Reducing information avoidance through affirmation. Psychological Science, 23(2), 141-145. https://doi.org/10.1177/0956797611424164

Howell, J. L., \& Shepperd, J. A. (2013). Behavioral obligation and information avoidance. Annals of Behavioral Medicine, 45(2), 258-263. https://doi.org/10.1007/s12160-012$9451-9$

Howell, J. L., \& Shepperd, J. A. (2016). Establishing an information avoidance scale. Psychological Assessment, 28(12), 1695-1708. https://doi.org/10.1037/pas0000315

Howell, J. L., \& Shepperd, J. A. (2017). Social exclusion, self-affirmation, and health information avoidance. Journal of Experimental Social Psychology, 68, 21-26. https://doi.org/10.1016/j.jesp.2016.05.005

Järvinen, H. J., Aarnio, M., Mustonen, H., Aktan-Collan, K., Aaltonen, L. A., Peltomäki, P., ... \& Mecklin, J. P. (2000). Controlled 15-year trial on screening for colorectal cancer in families with hereditary nonpolyposis colorectal cancer. Gastroenterology, 118(5), 829834. https://doi.org/10.1016/S0016-5085(00)70168-5

Jordan, J. J., Hoffman, M., Nowak, M. A., \& Rand, D. G. (2016). Uncalculating cooperation is used to signal trustworthiness. Proceedings of the National Academy of Sciences, 113(31), 8658-8663. https://doi.org/10.1073/pnas.1601280113

Keogh, L. A., Southey, M. C., Maskiell, J., Young, M. A., Gaff, C. L., Kirk, J., ... \& Hopper, J. L. (2004). Uptake of offer to receive genetic information about BRCA1 and BRCA2 mutations in an Australian population-based study. Cancer Epidemiology and Prevention Biomarkers, 13(12), 2258-2263.

Khoury, M. J., Coates, R. J., \& Evans, J. P. (2010). Evidence-based classification of recommendations on use of genomic tests in clinical practice: dealing with insufficient 
evidence. Genetics in Medicine, 12(11), 680-683.

https://doi.org/10.1097/GIM.0b013e3181f9ad55

Kinsler, J. J., Wong, M. D., Sayles, J. N., Davis, C., \& Cunningham, W. E. (2007). The effect of perceived stigma from a health care provider on access to care among a low-income HIVpositive population. AIDS Patient Care and STDs, 21(8), 584-592.

https://doi.org/10.1089/apc.2006.0202

Klein, W. M. P., Shepperd, J. A., Suls, J., Rothman, A. J., \& Croyle, R. T. (2015). Realizing the promise of social psychology in improving public health. Personality and Social Psychology Review, 19(1), 77-92. https://doi.org/10.1177/1088868314539852

Krueger, J. I. (2007). From social projection to social behaviour. European Review of Social Psychology, 18(1), 1-35. https://doi.org/10.1080/10463280701284645

Krueger, J. \& Clement, R. W. (1994). The truly false consensus effect: An ineradicable and egocentric bias in social perception. Journal of Personality and Social Psychology, 67, 596-610. doi: 10.1037//0022-3514.67.4.596

Krueger, J., \& Heck, P. R. (2019). Putting the $p$-value in its place. The American Statistician, https://psyarxiv.com/y49mp.

Krueger, J. I., \& Massey, A. L. (2009). A rational reconstruction of misbehavior. Social Cognition, 27(5), 786-812. https://doi.org/10.1521/soco.2009.27.5.786

Krueger, J. I., Massey, A. L., \& DiDonato, T. E. (2008). A matter of trust: From social preferences to the strategic adherence to social norms. Negotiation and Conflict Management Research, 1(1), 31-52. https://doi.org/10.1111/j.1750-4716.2007.00003.x 
Lakens, D., Adolfi, F. G., Albers, C. J., Anvari, F., Apps, M. A. J., Argamon, S. E., .. Zwaan, R. A. (2018). Justify your alpha. Nature Human Behaviour, 2(3), 168-171. https://doi.org/10.1038/s41562-018-0311-X

Landy, J. F., Piazza, J., \& Goodwin, G. P. (2016). When it's bad to be friendly and smart: the desirability of sociability and competence depends on morality. Personality and Social Psychology Bulletin, 42(9), 1272-1290. https://doi.org/10.1177/0146167216655984

Lawrence, M. A. (2016). ez: Easy Analysis and Visualization of Factorial Experiments. R package version 4.4-0. https://CRAN.R-project.org/package=ez

Leary, M. R., \& Kowalski, R. M. (1990). Impression management: A literature review and twocomponent model. Psychological Bulletin, 107(1), 34-47. https://doi.org/10.1037/00332909.107.1.34

Loewenstein, G. F., Thompson, L., \& Bazerman, M. H. (1989). Social utility and decision making in interpersonal contexts. Journal of Personality and Social Psychology, 57(3), 426-441. https://doi.org/10.1037/0022-3514.57.3.426

Malle, B. F., Guglielmo, S., \& Monroe, A. E. (2014). A theory of blame. Psychological Inquiry, 25(2), 147-186. https://doi.org/10.1080/1047840X.2014.877340

McAdams, D. P. (2013). The psychological self as actor, agent, and author. Perspectives on Psychological Science, 8(3), 272-295. https://doi.org/10.1177/1745691612464657

Melnyk, D., \& Shepperd, J. A. (2012). Avoiding risk information about breast cancer. Annals of Behavioral Medicine, 44(2), 216-224. https://doi.org/10.1007/s12160-012-9382-5

Mold, F., \& Forbes, A. (2013). Patients' and professionals' experiences and perspectives of obesity in health-care settings: a synthesis of current research. Health Expectations, 16(2), 119-142. https://doi.org/10.1111/j.1369-7625.2011.00699.x 
Nagel, T. (1979). Moral luck. Ethical theory: an anthology, 322-329.

Ndinya-Achola, J., Ambani, J., Temmerman, M., \& Piot, P. (1995). The right not to know HIVtest results. The Lancet, 345(8955), 969-970. https://doi.org/10.1016/S01406736(95)90707-6

Nightingale, S. D., Yarnold, P. R., \& Greenberg, M. S. (1991). Sympathy, empathy, and physician resource utilization. Journal of General Internal Medicine, 6(5), 420-423. https://doi.org/10.1007/BF02598163

Pantenburg, B., Sikorski, C., Luppa, M., Schomerus, G., König, H. H., Werner, P., \& RiedelHeller, S. G. (2012). Medical students' attitudes towards overweight and obesity. PloS one, 7(11), e48113. https://doi.org/10.1371/journal.pone.0048113

Patil, I. (2018). ggstatsplot: 'ggplot2' Based Plots with Statistical Details. R package version 0.0.3. https://CRAN.R-project.org/package=ggstatsplot

Phelan, S. M., Burgess, D. J., Yeazel, M. W., Hellerstedt, W. L., Griffin, J. M., \& van Ryn, M. (2015). Impact of weight bias and stigma on quality of care and outcomes for patients with obesity: Obesity stigma and patient care. Obesity Reviews, 16(4), 319-326. https://doi.org/10.1111/obr.12266

Puhl, R., \& Brownell, K. D. (2001). Bias, discrimination, and obesity. Obesity Research, 9(12), 788-805. https://doi.org/10.1038/oby.2001.108

Rebbeck, T. R., Kauff, N. D., \& Domchek, S. M. (2009). Meta-analysis of risk reduction estimates associated with risk-reducing salpingo-oophorectomy in $B R C A 1$ or $B R C A 2$ mutation carriers. Journal of the National Cancer Institute, 101(2), 80-87. https://doi.org/10.1093/jnci/djn442 
Rantanen, E., Hietala, M., Kristoffersson, U., Nippert, I., Schmidtke, J., Sequeiros, J., \& Kääriäinen, H. (2008). What is ideal genetic counselling? A survey of current international guidelines. European Journal of Human Genetics, 16(4), 445-452. https://doi.org/10.1038/sj.ejhg.5201983

Robinson, D. (2018). broom: Convert Statistical Analysis Objects into Tidy Data Frames. R package version 0.4.4. https://CRAN.R-project.org/package=broom

Rom, S. C., \& Conway, P. (2018). The strategic moral self: Self-presentation shapes moral dilemma judgments. Journal of Experimental Social Psychology, 74, 24-37. https://doi.org/10.1016/j.jesp.2017.08.003

Shen, M. J., Hamann, H. A., Thomas, A. J., \& Ostroff, J. S. (2016). Association between patientprovider communication and lung cancer stigma. Supportive Care in Cancer, 24(5), 2093-2099. https://doi.org/10.1007/s00520-015-3014-0

Sparkman, G., \& Walton, G. M. (2017). Dynamic norms promote sustainable behavior, even if it is counternormative. Psychological Science, 28(11), 1663-1674. https://doi.org/10.1177/0956797617719950

Spring, V. L., Cameron, C. D., McKee, S., \& Todd, A. R. (2018). Intentional and unintentional empathy for pain among physicians and nonphysicians. Social Psychological and Personality Science, online first. https://doi.org/10.1177/1948550618771890

Stigler, G. J. (1961). The economics of information. Journal of Political Economy, 69(3), 213225. https://doi.org/10.1086/258464

Street, R. L., Gordon, H., \& Haidet, P. (2007). Physicians' communication and perceptions of patients: Is it how they look, how they talk, or is it just the doctor? Social Science \& Medicine, 65(3), 586-598. https://doi.org/10.1016/j.socscimed.2007.03.036 
Sweeny, K., Melnyk, D., Miller, W., \& Shepperd, J. A. (2010). Information avoidance: Who, what, when, and why. Review of General Psychology, 14(4), 340.

Swets, J. A., Dawes, R. M., \& Monahan, J. (2000). Psychological science can improve diagnostic decisions. Psychological Science in the Public Interest, 1(1), 1-26. https://doi.org/10.1111/1529-1006.001

Torchiano, M. (2017). effsize: Efficient Effect Size Computation. R package version 0.7.1. https://CRAN.R-project.org/package=effsize

Van Dijk, E., Wilke, H., Wilke, M., \& Metman, L. (1999). What information do we use in social dilemmas? Environmental uncertainty and the employment of coordination rules. Journal of Experimental Social Psychology, 35(2), 109-135. https://doi.org/10.1006/jesp.1998.1366

Welkenhuysen, M., Evers-Kiebooms, G., \& Van den Berghe, H. (1997). Attitudes toward predictive testing for Alzheimer's disease in a student population. Behavioural Neurology, 10(4), 143-148. http://dx.doi.org/10.3233/BEN-1997-10408

White, M. \& Dorman, S.M. (2001). Receiving social support online: implications for health education. Health Education Research, 16(6), 693-707. https://doi.org/10.1093/her/16.6.693

Wickham, H. (2017). tidyverse: Easily Install and Load the 'Tidyverse'. R package version 1.2.1. https://CRAN.R-project.org/package=tidyverse

Wickham, H., \& Bryan, J. (2018). readxl: Read Excel Files. R package version 1.1.0. https://CRAN.R-project.org/package=readxl

Widdows, H. (2007). Conceptualising the self in the genetic era. Health Care Analysis, 15(1), 512. https://doi.org/10.1007/s10728-006-0033-5 
Wilke, C. (2017). cowplot: Streamlined Plot Theme and Plot Annotations for 'ggplot2'. R package version 0.9.2. https://CRAN.R-project.org/package=cowplot

Wilson, J. (2005). To know or not to know? Genetic ignorance, autonomy and paternalism. Bioethics, 19(5-6), 492-504. https://doi.org/10.1111/j.1467-8519.2005.00460.x

Wojciszke, B. (1994). Multiple meanings of behavior: Construing actions in terms of competence or morality. Journal of Personality and Social Psychology, 67(2), 222-232. http://dx.doi.org/10.1037/0022-3514.67.2.222

Yaniv, I., Benador, D., \& Sagi, M. (2004). On not wanting to know and not wanting to inform others: Choices regarding predictive genetic testing. Risk Decision and Policy, 9(4), $317-$ 336. 


\section{Appendix}

Table A1. Measures Collected in All Studies

\begin{tabular}{|c|c|c|}
\hline Measure & Question(s) & Scale \\
\hline Competence & $\begin{array}{l}\text { How Intelligent/Capable/Logical/Irrational is } \\
\text { [Target]? }\end{array}$ & $\begin{array}{l}1 \text { (Not at all) - } \\
5 \text { (Extremely) }\end{array}$ \\
\hline Morality & $\begin{array}{l}\text { How Trustworthy/Ethical/Principled/Irresponsible } \\
\text { is [Target]? }\end{array}$ & $\begin{array}{l}1 \text { (Not at all)- } \\
5 \text { (Extremely) }\end{array}$ \\
\hline Own preference & $\begin{array}{l}\text { If you were [Target], would you choose to view } \\
\text { this result? }\end{array}$ & $\begin{array}{l}1 \text { (Definitely not) - } \\
4 \text { (Definitely yes) }\end{array}$ \\
\hline $\begin{array}{l}\text { Normative } \\
\text { prescription }\end{array}$ & Did [Target] make the right choice? & $\begin{array}{l}1 \text { (Definitely not) - } \\
4 \text { (Definitely yes) }\end{array}$ \\
\hline $\begin{array}{l}\text { Free response } \\
\text { explanation* }\end{array}$ & $\begin{array}{l}\text { Why do you think [Target]'s choice was the right } \\
\text { or wrong one to make? }\end{array}$ & Free text entry \\
\hline Empathy & How much empathy do you have for [Target]? & $\begin{array}{l}1 \text { (None at all) - } \\
5 \text { (A great deal) }\end{array}$ \\
\hline Sympathy & How much sympathy do you have for [Target]? & $\begin{array}{l}1 \text { (None at all) - } \\
5 \text { (A great deal) }\end{array}$ \\
\hline $\begin{array}{l}\text { Information } \\
\text { Avoidance }\end{array}$ & $\begin{array}{l}\text { "Even if it will upset me, I want to know about..." } \\
\text { and "I would avoid learning about..." "...genetic } \\
\text { information that could be important to my health } \\
\text { (and the health of my family members)." }\end{array}$ & $\begin{array}{l}1 \text { (Strongly disagree) }- \\
7 \text { (Strongly agree) }\end{array}$ \\
\hline $\begin{array}{l}\text { Genetic disease } \\
\text { in family* }\end{array}$ & $\begin{array}{l}\text { Are you aware of any genetic diseases in your } \\
\text { family? }\end{array}$ & Yes or No \\
\hline $\begin{array}{l}\text { Genetic testing } \\
\text { in past* }\end{array}$ & Have you ever undergone genetic testing? & $\begin{array}{l}\text { Yes (medical procedure); } \\
\text { Yes (family planning); } \\
\text { Yes (my own curiosity); } \\
\text { No }\end{array}$ \\
\hline Demographics* & Sex, Race/Ethnicity, Age, Education, Income & See open materials \\
\hline
\end{tabular}

Note. In Study 1 only, the items for "own preference," "normative prescription," and "free response explanation" were modified to fit the context in two conditions where no decision was made (see Design \& Procedure). The final three measures were not collected from Geisinger providers (Study 4). Items with a $*$ symbol are not reported in the results but are made available as part of the open dataset. 